\title{
Hypophosphataemic osteomalacia due to de Toni-Debre-Fanconi syndrome in a 19-year old girl
}

\author{
Tasoula Tsilchorozidou, John G Yovos
}

Division of Endocrinology, Diabetes and Metabolism, AHEPA University Hospital, Thessaloniki, Greece

\begin{abstract}
Osteomalacia associated with adult onset Fanconi syndrome is thought to result from hypophosphataemia due to renal phosphate loss and relative 1,25-dihydroxyvitamin $D_{3}$ deficiency. In this disorder, the impaired renal phosphate uptake occurs as part of a generalized tubular defect in association with other features such as bicarbonuria, glycosuria and aminoaciduria. Fanconi syndrome is either hereditary-juvenile form-or is associated with various acquired or heritable diseases. In adults, the disease is similar to the juvenile form, but osteomalacia is a prominent feature. We report a sporadic, adult onset, hypophosphataemia in a 19-year old female patient who presented after puberty complaining of bone and joint pain and difficulty in walking following a minor fall. Radiological examination revealed numerous bilateral fractures of the ribs and pelvis while biochemical investigations showed combination of high phosphate clearance, low serum bicarbonate, glycosuria and glycinuria. Known causes of acquired renal tubular dysfunction were ruled out. The patient was diagnosed as having idiopathic Fanconi syndrome and started on vitamin $D_{3}$ (Alfacalcidol $1 \mathrm{mg} / \mathrm{day}$ ) and oral phosphorus (Joulie Solution, $1.5 \mathrm{~g} / \mathrm{day}$ ), which led to resolution of symptoms and an increase in serum phosphate (from 0,54 to $0,71 \mathrm{mmol} / \mathrm{l}$ ) within few months following the initiation of therapy. However, radiological re-examination showed no signs of fracture healing.
\end{abstract}

Key words: Hypophosphataemic osteomalacia, De Toni-Debre-Fanconi syndrome

\section{INTRODUCTION}

Fanconi syndrome occurs as part of defective tubular reabsorption of most aminoacids, glucose, urate, bicarbonate and phosphate, leading to renal tubular acidosis (RTA) and hypophosphataemic rickets/osteomalacia. Other abnormalities include

Address correspondence and requests for reprints to:

Dr T Tsilchorozidou, Department of Endocrinology, Diabetes and Metabolism, AHEPA University Hospital, 1 Stilp. Kiriakidi Str., 54006 Thessaloniki, Greece, Tel: 00302310 994607, Fax: 00302310 994608, e-mail: tasoula@med.auth.gr Received 23-04-05, Revised 20-06-05, Accepted 30-06-05 potassium depletion, primary or secondary to the acidosis, polyuria and increased excretion of immunoglobulins or other low-molecular-weight proteins. Various combinations of the above abnormalities have been described ${ }^{1,2}$. Osteomalacia associated with adult onset Fanconi syndrome is thought to result from hypophosphataemia due to renal phosphate wasting and relative 1,25-dihydroxyvitamin D deficiency ${ }^{2}$. The impaired phosphate uptake in these patients has been attributed to an intrinsic renal defect in the proximal tubules. Fanconi syndrome is either idiopathic (transmitted in an autosomal re- 
cessive pattern-juvenile form) or occurs in adult life, often due to various heritable or acquired disorders.

Children with Fanconi syndrome present clinically with growth failure and rickets. Fanconi syndrome has been associated with many heritable diseases, including lysosomal storage disease, Lowe's syndrome-a multi-system disorder affecting the central nervous system, the lenses and the kidneys-, and cystinosis, which is the most common inherited cause in the paediatric population ${ }^{2}$. Adults present with osteomalacia, which manifests as bone pain, proximal muscle weakness and spontaneous fractures ${ }^{3}$. Heavy metal poisoning, drugs and multiple myeloma are among the primary causes of Fanconi syndrome in adulthood ${ }^{2}$.

Disorders of renal phosphate loss may also result from a number of genetic disorders including $\mathrm{X}$-linked hypophosphataemic rickets/osteomalacia (XLH; mutations in PHEX gene on Xp22.1) ${ }^{4}$, hereditary hypophosphataemic rickets with hypercalciuria (HHRH), hypophosphataemic bone disease (HBD) and autosomal dominant hypophosphataemic rickets/osteomalacia (ADHR; mutations of FGF23 on $12 \mathrm{p} 13.3)^{5,6}$, as well as from a rare acquired disorder of oncogenic hypophosphataemic osteomalacia (TIO) $)^{7,8}$. All the above disorders, however, are characterized by an isolated defect of renal tubular reabsorption of phosphate and consequent hypophosphataemia. Although the similarities in phenotype, particularly between TIO and XLH, suggest an overlapping pathology, it has been difficult to determine a unifying hypothesis to explain the etiology of phosphate wasting in these disorders. Nevertheless, several observations suggest that the phosphate wasting is not due to an intrinsic tubular defect ${ }^{7,9}$.

\section{PATIENT'S DESCRIPTION}

A 19-yearold female patient was initially admitted to the Neurological Department of our Hospital for investigation of low back pain accompanied by some limitation of extension of both hips and lumbar spine. The severe back pain was impairing her posture, forcing her to walk slowly. She had been in good health until recently when symptoms started soon after a minor fall. On examination her height was found to be $150 \mathrm{~cm}$ and her weight $49 \mathrm{~kg}$, with a
BMI of $19.5 \mathrm{~kg} / \mathrm{m}^{2}$. The patient remarked that she had lost $12 \mathrm{~cm}$ in height over the past 3 years as her height had been previously registered as $162 \mathrm{~cm}$. There were no deformities of her lower extremities. The sensorimotor function of the upper body was found to be normal but there was conspicuous limitation in the mobility of the lower back and hips. Motor testing failed to detect any weakness. She had no sensory symptoms and the neurological examination was normal. Her paediatric history was negative for lower extremity deformities, fractures or tooth abscesses. There was no family history of rickets/osteomalacia in the current or previous generations. There was also no history of heavy metal poisoning or drug consumption.

\section{Biochemical investigations}

On admission, serum biochemistry revealed severe hypophosphataemia [phosphorus: $0,49 \mathrm{mmol} / 1$ $(1.54 \mathrm{mg} / \mathrm{dl})$; reference: $0,86-1,45 \mathrm{mmol} / \mathrm{l}$ (2.7-4.5 $\mathrm{mg} / \mathrm{dl})$, normal values of serum calcium $\mathrm{Ca}: 2.3$ $\mathrm{mmol} / \mathrm{l}(9.2 \mathrm{mg} / \mathrm{dl})$; reference: $2,1-2,63 \mathrm{mmo} / \mathrm{l}$ (8.4$10.5 \mathrm{mg} / \mathrm{dl})$, magnesium $\mathrm{Mg}: 0,8 \mathrm{mmol} / \mathrm{l}(2 \mathrm{mg} / \mathrm{dl})$; reference: $0,7-1,1 \mathrm{mmol} / \mathrm{l}(1,7-2.8 \mathrm{mg} / \mathrm{dL})$ and creatinine clearance at 1,55 and $1,42 \mathrm{~mL} / \mathrm{min}$ (94.1 and $86.2 \mathrm{ml} / \mathrm{min}$ ) on two occasions]. Uric acid in serum was low at $0.12 \mathrm{mmol} / \mathrm{l}(1,91 \mathrm{mg} / \mathrm{dl})$; reference 0.15 $0,36 \mathrm{mmol} / \mathrm{l}(2.4-6 \mathrm{mg} / \mathrm{dl})$. The alkaline phosphatase was elevated at $326 \mathrm{U} / \mathrm{L}$ (reference: $39-117 \mathrm{U} / \mathrm{L}$ ) with normal levels of intact PTH at 1,8 pmol/L (18 $\mathrm{pg} / \mathrm{ml})$; reference $1.3-6,4 \mathrm{pmol} / \mathrm{L}(13-64 \mathrm{pg} / \mathrm{ml})$ and $25(\mathrm{OH}) \mathrm{D}_{3}$ at $55 \mathrm{nmol} / \mathrm{l}(23 \mathrm{ng} / \mathrm{ml})$; reference: 24 $132 \mathrm{nmol} / \mathrm{l}(10-55 \mathrm{ng} / \mathrm{ml})$ and inappropriately 'normal' $1,25(\mathrm{OH})_{2} \mathrm{D}_{3}$ levels at $110 \mathrm{pmol} / \mathrm{L}(46 \mathrm{pg} / \mathrm{ml})$; reference: $48-160 \mathrm{pmol} / \mathrm{L}(20-67 \mathrm{pg} / \mathrm{ml})$ in view of the low serum phosphate concentration. Serum osteocalcin, which is considered to be an index of osteoblast function, was $20.3 \mu \mathrm{g} / \mathrm{l}$ (reference 5-18 $\mu \mathrm{g}$ / 1), while $2 \mathrm{~h}$ urinary excretion of hydrohyproline/creatinine, a marker of bone resorption, was $29 \mathrm{mg}$ (reference $<20 \mathrm{mg}$ ). Arterial $\mathrm{pH}$ was $7.32, \mathrm{PO}_{2}: 15.25 \mathrm{kPa}$ $(115.9 \mathrm{mmHg}), \mathrm{PCO}_{2}: 5.1 \mathrm{kPa}(38.4 \mathrm{mmHg})$, bicarbonate: $19.4 \mathrm{mmol} / \mathrm{L}, \mathrm{SBE}:-5.9 \mathrm{mmol} / \mathrm{L}$ and saturation: $97.9 \%$. Plasma glucose was $4.46 \mathrm{mmol} / \mathrm{l}(81$ $\mathrm{mg} / \mathrm{dl})$; reference $4.1-6.3 \mathrm{mmol} / \mathrm{l}(75-115 \mathrm{mg} / \mathrm{dl})$ and plasma proteins $78.3 \mathrm{~g} / \mathrm{L}$ (reference $66-87 \mathrm{~g} / \mathrm{L}$ ). Urine analysis showed specific gravity at $1022, \mathrm{pH}$ at 6 , glucose at $5.5 \mathrm{mmol} / \mathrm{l}(100 \mathrm{mg} / \mathrm{dl})$. No protein 
was detected and the microscopic examination was normal. There was also no evidence of Bence-Jones protein or other low-molecular-weight proteins in $24 \mathrm{~h}$ urine sample. Analysis of 24 hour collection on unrestricted dietary $\mathrm{Na}^{+}$intake (in Greek diet the average $\mathrm{Na}^{+}$intake is approximately $120 \mathrm{mmol} /$ day) was as follows:

- Urea 190 mmol/24h (reference: 170-600 mmol/ 24h)

- Creatinine $11.14 \mathrm{mmol} / 24 \mathrm{~h}$ (reference: 6.8-14 $\mathrm{mmol} / 24 \mathrm{~h}$ )

- Sodium $51 \mathrm{mmol} / 24 \mathrm{~h}$ (reference: $40-220 \mathrm{mmol} /$ 24h)

- Potassium $49 \mathrm{mmol} / 24 \mathrm{~h}$ (reference: $25-125$ $\mathrm{mmol} / 24 \mathrm{~h}$ )

- Uric acid $1.6 \mathrm{mmol} / 24 \mathrm{~h}$ (reference: $1.2-3 \mathrm{mmol} /$ 24h)

- Calcium 1.2-2.5 mmol/24h (reference: $<6.3$ $\mathrm{mmol} / 24 \mathrm{~h}$ )

- Phosphate $22.4 \mathrm{mmol} / 24 \mathrm{~h}$ (reference: 12.9-32 $\mathrm{mmol} / 24 \mathrm{~h}$ ), which is unusually high in view of the low serum phosphate concentration.

Glucose and aminoacids were assayed in fasting urine samples: urine glucose concentration was found to be $2.75,4.1$ and $5.5 \mathrm{mmol} / \mathrm{l}$ (50.75 and 100 $\mathrm{mg} / \mathrm{dl}$ ) on three occasions while an oral glucose tolerance test was normal. Urinary aminoacids analysis with thin layer chromatography (TLC) showed glycinuria. Plasma ammonium, lactic acid and quantitative measure of plasma aminoacids with high performance liquid chromatography (HPLC) were within normal levels excluding renal tubular transport defects due to cystinuria, Hartnup's disease, galactosaemia and fructosaemia. Thyroid hormones, which are known to influence both skeletal growth and renal tubular handling of phosphate ${ }^{10,11}$, were within normal limits.

\section{Indices of renal tubular reabsorption of phosphate:}

Indices of renal tubular reabsorption of phosphate were derived as follows:

- Phosphate Clearance: $\mathrm{C}_{\mathrm{PO} 4}=\mathrm{U}_{\mathrm{PO} 4} \times \mathrm{V}_{\text {urine/min }} / \mathrm{P}_{\mathrm{PO} 4}=31 \mathrm{ml} / \mathrm{min}$ (reference:
$11 \pm 2.5 \mathrm{ml} / \mathrm{min})$

- Phosphate/Creatinine Clearance ratio:

$$
\mathrm{C}_{\mathrm{PO} 4} / \mathrm{C}_{\mathrm{Cr}}=\mathrm{U}_{\mathrm{PO} 4} \times[\mathrm{Cr}] / \mathrm{U}_{\mathrm{Cr}} \times[\mathrm{PO} 4]=0.356
$$

- Fractional tubular reabsorption of phosphate: T.R.P. $=1-\mathrm{C}_{\mathrm{PO} 4} / \mathrm{C}_{\mathrm{Cr}}=1-0.356=0.644$ (reference: $0.78-0.90)$

$\mathrm{U}_{\mathrm{PO} 4}=$ urine phosphate concentration, $\mathrm{U}_{\mathrm{Cr}}=$ urine creatinine concentration, $[\mathrm{PO} 4]=$ plasma phosphate, $[\mathrm{Cr}]=$ plasma creatinine (all expressed in consistent units).

The nomogram of R.J. Walton and O.L.M. Bijvoet ${ }^{12}$ for derivation of renal threshold phosphate concentration was used to calculate renal threshold phosphate concentration (TmPO4/GFR). This ratio of maximum rate of renal tubular reabsorption of phosphate to GFR is independent of GFR and of net inflow of phosphate. A straight line through the appropriate values of [PO4] and T.R.P. passes through the corresponding value of TmPO4/GFR. In our case it was found to be low at $0.43 \mathrm{mmol} / \mathrm{l}$ (1.15 mg per $100 \mathrm{~mL})$; reference: $0.8-1.35 \mathrm{mmol} / \mathrm{l}$ (2.5-4.2 $\mathrm{mg}$ per $100 \mathrm{~mL})$.

\section{Radiographic findings}

Chest-X-Ray revealed numerous bilateral fractures of the ribs. Plain films also documented bilateral fractures of the superior aspect of the pubic rami with angulations, fracture of the medial aspect of the left fibula and a possible fracture of the $S_{1}$ vertebra. There was no loss of lamina dura or dental disease. A bone scintigraphy showed increased uptake at multiple sites including the areas of rib fractures, sacroiliac joints bilaterally, the body of $S_{1}$ vertebra and the proximal end of the left fibula. Bone mineral density measured by dual X-Ray absorptiometry (DEXA) revealed severe decrease at the lumbar spine $\left(\mathrm{L}_{1}-\mathrm{L}_{4}: 0.473 \mathrm{~g} / \mathrm{m}^{2}\right)$. CT of pelvis and MRI scan of lumbar spine/sacrum confirmed the existence of the fractures.

Electromyography showed no abnormality while nerve conduction studies showed $S_{1}$ and $S_{2}$ root lesions. Finally, an Indium ${ }^{111}$-Octreotide scan showed no focal uptake.

\section{Management}

The patient was started on a combination of vi- 
tamin D (alphacalcidol $1 \mu \mathrm{g} / \mathrm{Day}$ ) and oral phosphorus $1.5 \mathrm{~g} /$ Day in five divided doses [oral phosphorus was given as a mixture of dibasic sodium phosphate (136g of NaHPO4) and phosphoric acid (58.8g of H3PO4) in one liter of water; Joulie Solution: Nelson, $15^{\text {th }}$ edition $^{13}$ ], which led to resolution of symptoms, especially regarding bone pain and increase in serum phosphorus [from 0.54 to $0.71 \mathrm{mmol} / \mathrm{L}$ (1.7 to $2.2 \mathrm{mg} / \mathrm{dl})$ ] within six months of therapy initiation. Serum calcium was normal at $2.25 \mathrm{mmol} / \mathrm{L}(9$ $\mathrm{mg} / \mathrm{dl}$ ) and $24 \mathrm{~h}$ urine calcium remained within normal range at $4.5 \mathrm{mmol} / 24 \mathrm{~h}(180 \mathrm{mg} / 24 \mathrm{~h})$. PTH (intact) also remained within normal range at $3.8 \mathrm{pmol} /$ $\mathrm{L}(36 \mathrm{pg} / \mathrm{ml})$. On repeat evaluation after completion of one year on treatment there was further improvement, especially regarding her ability to climb stairs or rise from a chair. However, radiological reexamination showed no signs of fracture healing.

\section{DISCUSSION}

In this report we describe a rare case of adult onset non-familial Fanconi syndrome in a 19-year old girl who presented with a clinical picture of osteomalacia, including lower back pain, pseudofractures and walding gait. Osteomalacia and Fanconi syndrome were diagnosed almost concurrently in our patient, as is customarily reported in the literature $^{14}$. Hypophosphataemia, inappropriately low 1.25-dihydroxyvitamin $\mathrm{D}_{3}$ levels, renal insufficiency and chronic acidosis due to bicarbonate loss contribute to osteomalacia in such patients ${ }^{14-17}$.

Hypophosphataemia is seen in several metabolic bone disorders that should be distinguished from Fanconi syndrome. Hypophosphataemic disorders mimicking Fanconi syndrome are nutritional vitamin D deficiency or malabsorption, vitamin D-dependent rickets (type 1 and 2), primary hyperparathyroidism, impaired intestinal Phosphorous absorption (use of binders), X-linked hypophosphataemic rickets/osteomalacia (XLH) ${ }^{4}$, hereditary hypophosphataemic rickets with hypercalciuria (HHRH), hypophosphataemic bone disease (HBD), autosomal dominant hypophosphataemic rickets/osteomalacia (ADHR) $)^{5,6}$, as well as a rare acquired disorder of oncogenic hypophosphataemic osteomalacia. The diagnosis can be established by showing the biochemical abnormalities noted above: a reduced tubular re-absorption of phosphate, glycosuria with normal plasma glucose concentrations and aminoaciduria ${ }^{2}$. Because some patients will have phosphorous values that fall within the low normal range, it is useful to calculate the fractional excretion of phosphorous, which will be elevated in Fanconi syndrome.

X-linked hypophosphataemia, the most common form of familial hypophosphataemic rickets and osteomalacia in Westerns countries, shares many characteristics with Fanconi syndrome. However, in $\mathrm{XLH}$, phosphate loss is caused by abnormal regulation of sodium phosphate co-transport in the proximal tubules, while in Fanconi syndrome it is due to an intrinsic renal defect ${ }^{4-9}$. The phenotype is variable, but includes lower extremity deformity, short stature, bone pain, enthesopathy and radiographic evidence of rickets and osteomalacia. Affected adults primarily present dental disease, osteoarthritis-mainly bone and joint pain-and painful pseudofractures. The syndrome usually appears as an Xlinked dominant trait with onset during childhood but may occur sporadically in adult life. Inactivating mutations of the PHEX gene (from the HYP region in Xp22.1) with homologies to endopeptidases are responsible for $\mathrm{XLH}^{4}$.

Secondary Fanconi syndrome has also been reported in monoclonal disorders including multiple myeloma or lymphoma and lead poisoning or to be drug-induced following fumarate therapy in psoriasis and ingestion of 3-methylchromone ${ }^{2}$. Cystinosis constitutes another cause of Fanconi syndrome, which when presented in the adult form, is usually benign. Regardless of the underlying cause, osteomalacia associated with adult Fanconi's syndrome appears to respond well to phosphate and vitamin D replacement ${ }^{14-16}$. Furthermore, Clarke and coworkers reported that from 8 patients in whom follow-up data were available, only one developed endstage renal failure after 20 years, suggesting that these patients do not invariably progress to renal failure ${ }^{14}$.

Until as recently as 1980, the standard therapy for hypophosphataemic osteomalacia/rickets consisted of high doses of vitamin D and phosphate sup- 
plementation to maintain the serum phosphate concentration above the lower normal range ${ }^{18}$. A constant concern of physicians who treat these patients are the complications of hypercalcemia, hypercalciuria, nephrocalcinosis and nephrolithisis, some or all of which are associated with progressive deterioration of renal function. Therefore, patients should be frequently monitored with serum calcium and phosphorus determinations, as well as urine calcium/creatinine ratios. In order to avoid the risk of hyperparathyroidism that is occasionally encountered due to phosphate supplementation without the suppressive effects of concomitant 1,25-dihydroxyvitamin $\mathrm{D}_{3}$ administration, intact (1-84) PTH concentrations should be determined once or twice a year. In our patient, while the above combination of treatment based on the experience with other forms of hypophosphataemic osteomalacia was clinically effective leading to resolution of symptoms, an unexplained lack of bone healing was noted. One explanation could be that the bone disease in our patient was worsened by the presence of acidosis. RTA is commonly seen in these patients. It is usually a type II RTA, although defects in $\mathrm{H}^{+}$ion excretion may also be present. It is assumed that phosphaturia and hypophosphataemia play a major role in the development of rickets/osteomalacia. However, acidosis can cause bone disease independent of phosphate depletion. Acute and chronic acidosis induces demineralization of bone and increased urinary loss of calcium ${ }^{17}$. Patients with RTA have lower BMD and increased osteoid volume compared with reference values ${ }^{15}$ and alkali therapy can, most likely, improve RTA-associated osteomalacia ${ }^{19}$.

DEXA is widely accepted as a quantitative measurement technique for assessing skeletal status in postmenopausal women. While the T-score is a standard component of DEXA BMD results, it is clearly inappropriate to assess skeletal health in young people through comparison with peak adult bone mass. At present, there are no evidence-based guidelines for classification of bone integrity in this age group. Despite the growing body of normative data, there is little agreement on the quantitative definition of osteopenia and osteoporosis in youth. BMD reference data sets used to calculate Z-scores include a small number of normal individuals within each age category and do not accurately characterize normal variability in $\mathrm{BMD}^{20}$. Although measurements of the lumbar spine by DEXA is relatively new, there is a growing amount of clinical experience derived by using the lumbar spine to monitor children and young adults with bone mineral disorders. This was actually our initial thought when we performed DEXA in our patient. However, for adequate evaluation of overall bone mineral status, both cortical and trabecular sites (lumbar spine and radial diaphysis) should be examined. To date no data suggest that additional pharmacologic intervention with bisphosphonates, calcitonin or oestrogen analogues has any value in the premenopausal, oestrogen-replete woman ${ }^{20}$.

Over the last few years, the wider availability of recombinant human growth hormone has led to its use as a new therapeutic approach ${ }^{21}$. The rationale for the administration of $\mathrm{GH}$ is that exogenous $\mathrm{GH}$ can promote tubular reabsorption of phosphate alone or in conjunction with 1.25-dihydroxy-vitamin $\mathrm{D}_{3}$ and phosphate treatment. This regimen can promote normalization of serum phosphate, healing of pseudofractures and acceleration of linear growth in young patients while avoiding some of the treatment-related complications currently being encountered.

In conclusion, treatment of Fanconi syndromeinduced bone disease should be based on its underlying cause. If the associated disease can be treated or offending agent removed, Fanconi syndrome may resolve and the metabolic bone disease remit. Phosphate and calcium replacement have been reported to improve osteomalacia and rickets associated with Fanconi syndrome. Alkali therapy can improve RTAassociated osteomalacia in those patients who also develop chronic acidosis.

\section{REFERENCES}

1. Scriver CR, Beaudet AL, Sly WS, Valle D 1989 The Metabolic Basis of Inherited Disease, McGraw-Hill (eds) New York.

2. Tebben PJ, Kumar R 2003 Fanconi syndrome and renal tubular acidosis. In: Primer on the metabolic bone diseases and disorders of mineral metabolism ASBMR (ed) pp, 426-430.

3. Kumar P, Clark M 1996 Clinical Medicine, W B Saun- 
ders (eds) London; pp, 863.

4. The HYP Consortium, 1995 A gene (PHEX) with homologies to endopeptidases is mutated in patients with X-linked hypophosphatemic rickets. Nature Genetics 11: 130-136.

5. Econs MJ, McEnery PT, 1997 Autosomal dominant hypophosphatemic rickets/osteomalacia: clinical characterization of a novel renal phosphate-wasting disorder. J Clin Endocrinol Metab 82: 674-681.

6. The ADHR Consortium, 2000 Autosomal dominant hypophosphatemic rickets is associated with mutations in FGF23. Nature Genetics 26: 345-348.

7. White KE, Jonsson KB, Carn G, et al, 2001 Autosomal dominant hypophosphatemic rickets gene is a secreted polypeptide overexpressed by tumours that cause phosphate wasting. J Clin Endocrinol Metab 86: 497-500.

8. Quarles LD, Drezner MK, 2001 Pathophysiology of X-linked hypophosphatemia, tumour-induced osteomalacia, and autosomal dominant hypophosphatemia: A PerPHEXing problem. J Clin Endocrinol Metab 86: 494-495.

9. Nesbitt T, Drezner MK, 1997 Phosphate transport in renal cell cultures of gy mice: evidence of a single defect in X-linked hypophosphatemia Am J Physiol. 273: F113-F119.

10. Yusufi AN, Murayama N, Keller MJ, Dousa TR, 1985 Modulatory effect of thyroid hormones on uptake of phosphate and other solutes across luminal brush border membrane of kidney cortex. Endocrinology 116: 2438-2449.

11. Prasad R, Kumar V, 2005 Thyroid hormones stimulate $\mathrm{Na}+$-Pi transport activity in rat renal brush-border membranes: role of membrane lipid composition and fluidity. Mol Cell Biochem 268: 75-82.

12. Walton RJ, Bijvoet OLM, 1975 Nomogram for derivation of renal threshold phosphate concentration. Lancet 16: 309-310.

13. Chesney RW 1996 Familial hypophosphataemia. In: Nelson's textbook of Paediatrics, WB Saunders (eds), London; p, 1987.

14. Clarke BL, Wynne AG, Wilson DM, Fitzpatrick LA, 1995 Osteomalacia associated with adult Fanconi's syndrome: clinical and diagnostic features. Clin Endocrinol 43: 479-490.

15. Dalmak S, Erek E, Serdengecti K, Okar I, Ulku U, Basaran M, 1996 A case study of adult-onset hypophosphataemic osteomalacia with idiopathic Fanconi syndrome. Nephron 72: 121-122.

16. Harrison NA, Bateman JM, Ledingman JG, Smith R, 1991 Renal failure in adult onset hypophosphataemic osteomalacia with Fanconi syndrome: a family study and review of the literature. Clin Nephrol 35: 148-150.

17. Eiam-ong S, Kurtzman NA, 1994 Metabolic acidosis and bone disease. Miner Electrolyte Metab 20: 72-80.

18. Hanna JD, Niimi K, Chan JCM, 1991 X-linked Hypophosphatemia; Genetics and Clinical correlate AJDC 145: 865-870.

19. Richards P, Chamberlain MJ, Wrong OM, 1972 Treatment of osteomalacia of renal tubular acidosis by sodium bicarbonate alone. Lancet 2: 994-997.

20. Miller PD, Bonnick MD 2003 Clinical application of bone densitometry. In: Primer on the metabolic bone diseases and disorders of mineral metabolism ASBMR (ed) pp, 152-159.

21. Wilson DM, Lee PDK, Marcus R, 1990 Growth hormone therapy in familial hypophosphataemia Pediatric Research 27:195. 